\title{
Formulation Development of a Carrageenan Based Delivery System for Buccal Drug Delivery Using Ibuprofen as a Model Drug
}

\author{
Farnoosh Kianfar, Milan D. Antonijevic, Babur Z. Chowdhry, Joshua S. Boateng*
}

School of Science, University of Greenwich at Medway, Kent, UK.

E-mail: ${ }^{*}$ j.s.boateng@gre.ac.uk, ${ }^{*}$ joshboat@hotmail.com

Received September $20^{\text {th }}, 2011$; revised October $26^{\text {th }}, 2011$; accepted November $20^{\text {th }}, 2011$.

\begin{abstract}
Solvent cast films are used as oral strips with potential to adhere to the mucosal surface, hydrate and deliver drugs across the buccal membrane. The objective of this study was the formulation development of bioadhesive films with optimum drug loading for buccal delivery. Films prepared from $\kappa$-carrageenan, poloxamer and polyethylene glycol or glycerol, were loaded with ibuprofen as a model water insoluble drug. The films were characterized using texture analysis (TA), hot stage microscopy (HSM), differential scanning calorimetry (DSC), thermogravimetric analysis (TGA), scanning electron microscopy (SEM), x-ray powder diffraction (XRPD), high performance liquid chromatography (HPLC) and in vitro drug dissolution. Optimized films were obtained from aqueous gels containing $2.5 \% \mathrm{w} / \mathrm{w} \kappa$-carrageenan 911, 4\% w/w poloxamer 407 and polyethylene glycol (PEG) 600 [5.5\% w/w (non-drug loaded) and 6.5\% w/w (drug loaded)]. A maximum of $0.8 \% \mathrm{w} / \mathrm{w}$ ibuprofen could be incorporated into the gels to obtain films with optimum characteristics. Texture analysis confirmed that optimum film flexibility was achieved from $5.5 \% \mathrm{w} / \mathrm{w}$ and $6.5 \%(\mathrm{w} / \mathrm{w})$ of PEG 600 for blank films and ibuprofen loaded films respectively. TGA showed residual water content of the films as approximately $5 \%$. DSC revealed a $T_{g}$ for ibuprofen at $-53.87^{\circ} \mathrm{C}$, a unified $T_{m}$ for PEG 600/poloxamer mixture at $32.74^{\circ} \mathrm{C}$ and the existence of ibuprofen in amorphous form, and confirmed by XRPD. Drug dissolution at a pH simulating that of saliva showed that amorphous ibuprofen was released from the films at a faster rate than the pure crystalline drug. The results show successful design of a carrageenan and poloxamer based drug delivery system with potential for buccal drug delivery and showed the conversion of crystalline ibuprofen to the amorphous form during film formation.
\end{abstract}

Keywords: Carrageenan, Drug Dissolution, Physical Characterization, Plasticizer, Poloxamer

\section{Introduction}

The oral route is the most common means of administering pharmacological agents [1] because of advantages such as economy, convenience and patient compliance. However, it also presents major disadvantages such as first pass effect, gastrointestinal enzymatic degradation and delay between the time of administration and absorption which is detrimental in the case of drugs with rapid onset requirements. The foregoing factors have resulted in the exploration of alternative routes for the delivery of drugs [2] such as the buccal mucosa which may help to overcome the aforementioned challenges and improve drug bioavailability. Buccal delivery avoids liver first pass metabolism and GI enzymatic degradation and able to transfer drug relatively quickly via the systemic circulation to the site of action $[3,4]$. Since the drug content within the buccal formulations can be considerably lower than tablets and capsules, toxicity or undesired side effects will potentially be significantly reduced.

However, there are other limiting factors which need careful consideration, including drug solubility and formulation bioadhesivity to achieve efficient drug delivery and the desired systemic bioavailability. Films have potential as buccal drug delivery systems owing to their ease of administration (currently used as fast dissolving oral strips) and ease of hydration on contact with mucosal surfaces to allow drug diffusion out of the swollen gel [5]. However, they are limited by low drug loading capacity because of their thin nature [6]. In addition, not all film forming polymers are bioadhesive and improvements in bioadhesivity of such formulations 
can be achieved by employing hydrogel polymers with several hydrogen bonding sites which interact with functional groups of high molecular weight glycoproteins located on the surface of buccal tissues [7,8].

The current report discusses the development, optimization and characterization of a polymeric solvent cast film containing carrageenan and poloxamer (polymers), polyethyleneglycol (PEG) and glycerol (GLY) (plasticizers) and ibuprofen as a model drug for buccal drug delivery. Ibuprofen has been reported to be a suitable model drug in terms of its permeability $(\log \mathrm{P})$ properties [9]. Formulation development involved determining the amounts of carrageenan, poloxamer and the plasticizer (PEG or glycerol) required to achieve optimum films. In addition experiments were conducted in order to achieve maximum drug loading in the optimized films prior to tensile characterization (TA), water content thermogravimetry (TGA), stability and the physical form of the drug (DSC, HSM, XRPD) as well as drug dissolution studies.

Hydrogel polymers used included various grades of carrageenan: NF911, 812 ( $\kappa)$ and 379 (1) with the monomer chemical structure shown in Figure 1(a). Carrageenan is a sulphated polysaccharide produced from red seaweed (Rhodophyceae). Based on the number of sulphate groups per repeat unit of polysaccharide, it is classified into three different grades: kappa $(\kappa)$, iota (1) and lambda $(\lambda)$ with one, two or three sulphate groups, respectively [10]. All grades of carrageenan produce a thermo reversible sol-gel in aqueous solution which undergoes dispersion following random-coil formation in the sol stage. Carrageenan as a natural polymer has been widely employed in the food industry. However, it has not been used extensively in pharmaceutical applications, although $\kappa$-carrageenan has previously been demonstrated to have desirable properties for use in pharmaceutical formulations. At low temperature, galactose sequences within the carrageenan chains twist in a double helix fashion [11]. The sweet taste of galactose may help to mask the bitter taste of some drugs thus avoiding the need for flavoring and sweetening agents. Previous reports have also confirmed an increase in drug bioavailability [12] of $\kappa$-carrageenan. However, the major reason for its selection was the availability of several sites for hydrogen bonding which impart bioadhesive properties to the final formulation. In addition, the mucoadhesive property could be further enhanced by the negative charge of the sulphate group in the carrageenan structure forming ionic bonds with the positively charged mucin present on the buccal mucosa.

The other polymer employed was poloxamer 407 with the molecular formula $\left[\mathrm{HO}\left(\mathrm{C}_{2} \mathrm{H}_{4} \mathrm{O}\right)_{101}\left(\mathrm{C}_{3} \mathrm{H}_{6} \mathrm{O}\right)_{56}\left(\mathrm{C}_{2} \mathrm{H}_{4} \mathrm{O}\right)\right.$ $\left.{ }_{101} \mathrm{H}\right]$ and chemical structure shown in Figure 1(b). It is a block co-polymer containing ethylene and propylene oxide. Poloxamer 407 is a non-ionic surfactant with the ability to increase the solubility of drugs (e.g. ibuprofen) with high $\log \mathrm{P}$ and has been employed to achieve different drug release profiles [13-16]. Previous studies have shown that the erosion of poloxamer-based gels, in aqueous media, is relatively fast and it also exhibits mucosal permeation enhancing properties [17]. Plasticizers employed were polyethylene glycol 600 (Figure 1(c)) which is a hydrophilic polymer constituted of oxyethylene monomers [18] and glycerol (Figure 1(d)), with three hydroxyl groups, that dissolves in water and disrupts the hydrogen bonding between carrageenan chains.

\section{Materials and Methods}

\subsection{Materials}

$\kappa$-carrageenan (Gelcarin NF 911, batch number: 50102070 and Gelcarin 812 batch number: 80402170) and t-carrageenan (Gelcarin NF379, batch number: 40021170) were gifts from BASF (Surrey, UK). Poloxamer 407 (batch number: 038k0071) polyethylene glycol 600, batch number: 0001409391 (PEG), ibuprofen (batch number: 026H1368) and glycerol (batch number: RB12720) were all purchased from Sigma-Aldrich (Gillingham, UK) and used as received.

\subsection{Formulation Development}

Initial experiments involved investigating optimum gel preparation prior to film formation. These initial experiments were performed to determine the optimum combinations of the various polymers and plasticizers to produce films for drug incorporation (Table 1(a)).

Gel formulation involved three main approaches.

1) Carrageenan $(911,812$ or 379$)$ was added to magnetically stirred hot deionised water $\left(80^{\circ} \mathrm{C}\right)$ and stirring continued until a uniform gel was obtained. Poloxamer 407 and PEG 600 or glycerol, were then added to the resulting carrageenan gel and stirring continued with heating for 30 minutes.

2) The required amount of deionizer water was divided into two equal portions. One portion was heated to $60^{\circ} \mathrm{C}$ and carrageenan added with continuous stirring for 10 minutes. Poloxamer and plasticizer (PEG 600 or glycerol) were dissolved in the second portion, stirred for 5 minutes to produce a clear solution and then gently added to the initially prepared carrageenan gel.

3) Poloxamer 407 was dissolved in cold water $\left(<15^{\circ} \mathrm{C}\right)$ for two hours before addition of carrageenan to the resulting solution and left overnight at $40^{\circ} \mathrm{C}-50^{\circ} \mathrm{C}$ to ensure complete hydration of carrageenan. The final gel was obtained by addition of plasticizer (PEG 600 or 


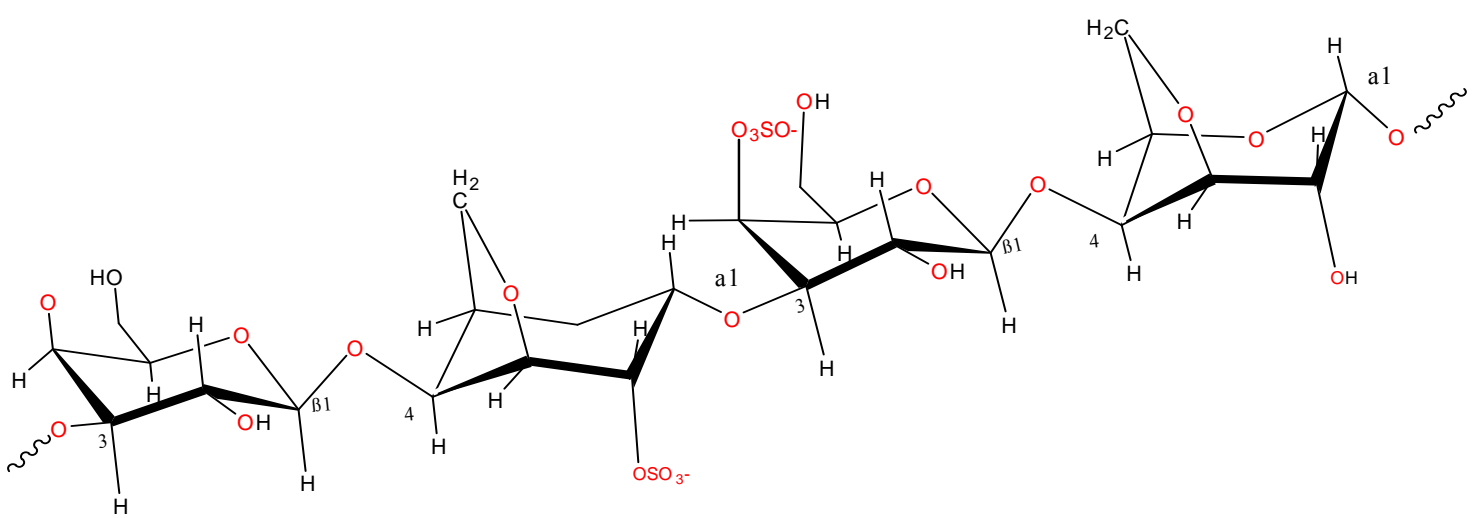

(a) carrageenan 911

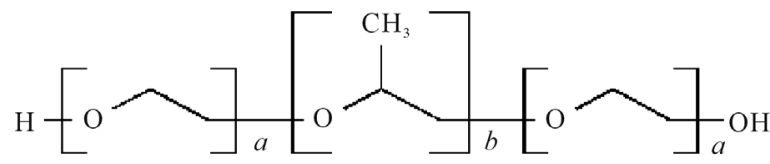

(b) poloxamer 407

$\mathrm{HO} \overbrace{\mathrm{O}}^{\mathrm{OH}}$

(c) polyethylene glycol (PEG 600)<smiles>OCC(O)CO</smiles>

(d) glycerol<smiles>CC(C)Cc1ccc(C(C)C(=O)O)cc1</smiles>

(e) ibuprofen

Figure 1. Chemical structures of the raw materials (a) к-carrageenan 911; (b) poloxamer 407; (c) polyethylene glycol; (d) glycerol and (e) ibuprofen used for formulating the optimized films.

glycerol) at a temperature of $40^{\circ} \mathrm{C}-50^{\circ} \mathrm{C}$ with continuous stirring.

Selected formulations comprising $2.5 \% \mathrm{w} / \mathrm{w}$ carrageenan $911,4 \% \mathrm{w} / \mathrm{w}$ poloxamer 407 and varying concentrations of PEG $600(5.0 \%-6.5 \%$ w/w $)$ or GLY $(4.5 \%-5.5 \% \mathrm{w} / \mathrm{w})$ were identified for drug incorporation (Table 1(b)). Two strategies were evaluated based on the maximum amount of ibuprofen that could be loaded without being visible (to the naked eye) on the film surface.

1) Ibuprofen $(0.3 \%-1.0 \% \mathrm{w} / \mathrm{w})$ was added to $4 \% \mathrm{w} / \mathrm{w}$ poloxamer 407 solution $\left(<15^{\circ} \mathrm{C}\right)$, kept for 2 hours before addition of carrageenan $2.5 \% \mathrm{w} / \mathrm{w}$ and plasticizer PEG $600(5.0 \%-6.5 \% \mathrm{w} / \mathrm{w})$ or GLY $(4.5 \%-5.5 \% \mathrm{w} / \mathrm{w})$ and 
Table 1. Composition of the gels prepared (approach 3) during film formulation development and optimization process.

\begin{tabular}{|c|c|c|}
\hline $\begin{array}{l}\text { (a) } \% \text { composition } \\
\text { various grades of } \kappa- \\
\text { GLY (NB: The form }\end{array}$ & $\begin{array}{l}\text { f gels containing } p \\
\text { irrageenan (CAR } 8 \\
\text { lations contained nn }\end{array}$ & $\begin{array}{l}\text { amer } 407 \text { (POL) with } \\
\text { 911, 379) PEG } 600 \text { or } \\
\text { uprofen) }\end{array}$ \\
\hline CAR $(\% \mathrm{w} / \mathrm{w})$ & POL $407(\% \mathrm{w} / \mathrm{w})$ & Plasticizer $(\% \mathrm{w} / \mathrm{w})$ \\
\hline $2.5(911)$ & 4 & 3.5 PEG \\
\hline $1.5(812,911,379)$ & 2 & 4.5 PEG \\
\hline $1.5(812,911,379)$ & 3 & 4.5 PEG \\
\hline $1.5(812,911)$ & 5 & 4.5 PEG \\
\hline $1.5(812,911)$ & 6 & 4.5 PEG \\
\hline $1.5(812,911)$ & 7 & 4.5 PEG \\
\hline $2.5(812,911)$ & 4 & 5.0 PEG \\
\hline $1.5(812,911)$ & 4 & 5.5 PEG \\
\hline $2.5(812,911)$ & 4 & 5.5 PEG \\
\hline $2.5(812,911)$ & 4 & 6.0 PEG \\
\hline $2.5(812)$ & 4 & 6.5 PEG \\
\hline $2.5(911)$ & 4 & 6.5 PEG \\
\hline $1.5(812,911)$ & 4 & $5.0 \mathrm{GLY}$ \\
\hline $1.5(812,911)$ & 4 & $5.5 \mathrm{GLY}$ \\
\hline $2.5(812,911)$ & 4 & $5.0 \mathrm{GLY}$ \\
\hline $2.5(812,911)$ & 4 & $5.5 \mathrm{GLY}$ \\
\hline
\end{tabular}

(b) Selected optimised gels containing $2.5 \% \mathrm{w} / \mathrm{w}$ к-carrageenan $(911 \& 812)(\mathrm{CAR}), 4 \%$ w/w poloxamer 407 (POL) and plasticizers (GLY or PEG 600) loaded with different amounts of ibuprofen

\begin{tabular}{cccc}
\hline CAR $(\% \mathrm{w} / \mathrm{w})$ & POL $407(\% / \mathrm{w})$ & plasticizer $\% \mathrm{w} / \mathrm{w})$ & ibuprofen $(\% \mathrm{w} / \mathrm{w})$ \\
\hline $2.5(911)$ & 4 & $5.0 \mathrm{PEG}$ & 0.3 \\
$2.5(812)$ & 4 & $5.0 \mathrm{PEG}$ & 0.3 \\
$2.5(911)$ & 4 & $5.0 \mathrm{PEG}$ & 0.4 \\
$2.5(812)$ & 4 & $5.0 \mathrm{PEG}$ & 0.4 \\
$2.5(812,911)$ & 4 & $5.5 \mathrm{PEG}$ & 0.3 \\
$2.5(812,911)$ & 4 & $5.5 \mathrm{PEG}$ & 0.4 \\
$2.5(911)$ & 4 & $5.5 \mathrm{PEG}$ & 0.4 \\
$2.5(911)$ & 4 & $5.5 \mathrm{PEG}$ & 0.8 \\
$2.5(911)$ & 4 & $5.5 \mathrm{PEG}$ & 1.0 \\
$2.5(911)$ & 4 & $6.5 \mathrm{PEG}$ & 0.8 \\
$2.5(911)$ & 4 & $6.5 \mathrm{PEG}$ & 1.0 \\
$2.5(812,911)$ & 4 & $4.5 \mathrm{GLY}$ & 0.3 \\
$2.5(812)$ & 4 & $5.0 \mathrm{GLY}$ & 0.3 \\
$2.5(911)$ & 4 & $5.0 \mathrm{GLY}$ & 0.3 \\
$2.5(812)$ & 4 & $5.0 \mathrm{GLY}$ & 0.3 \\
$2.5(911)$ & 4 & $5.0 \mathrm{GLY}$ & 0.3 \\
$2.5(812,911)$ & 4 & $5.5 \mathrm{GLY}$ & 0.4 \\
$2.5(812,911)$ & 4 & $5.5 \mathrm{GLY}$ & 0.8 \\
$2.5(812,911)$ & 4 & $5.5 \mathrm{GLY}$ & 1.0 \\
\hline & & &
\end{tabular}

left for 24 hours. This was undertaken with the aim of increasing drug incorporation based on the surfactant properties of poloxamer 407 .

2) Ibuprofen $(0.3 \%-1.0 \% \mathrm{w} / \mathrm{w})$ was dissolved separately in $2 \mathrm{ml}$ of ethanol and the resulting solution added to the gel comprising $2.5 \% \mathrm{w} / \mathrm{w}$ carrageenan $911,4 \%$ w/w poloxamer 407 and $5.0 \%-6.5 \%$ PEG 600 or $4.5 \%$ $5.5 \% \mathrm{w} / \mathrm{w}$ GLY prepared as in (III) above.

The resulting gels were poured into Petri dishes and placed in a vacuum oven at $60^{\circ} \mathrm{C}$. To determine the maximum time required for complete drying, the weight loss of the films was measured every 24 hours up to 72 hours until a constant weight was achieved.

\subsection{Texture Analysis (TA)}

Texture analysis was used to investigate the tensile properties (tensile strength, elastic modulus and percentage elongation) of the films (PEG plasticised) selected from initial formulation development. The results were used to aid in the selection of optimised films (as described above) with acceptable flexibility for drug loading and to determine effect of increasing drug content. Films containing 3.5\% - 6.5\% w/w PEG 600 were stretched to determine the effect of PEG 600 on tensile properties. Before tensile measurements, the thickness of the films was measured by a micrometer screw gauge in five different areas of each sample (four edges and one in the middle) and showed thickness ranging from $0.33-0.37 \mathrm{~mm}$. The exact thickness of each particular specimen was entered into the texture analyser software prior to stretching. The films were cut into dumb-bell shaped strips and stretched between tensile rigs of the texture analyser (HTI, Hounsfeild, Germany) to break point. The following settings were used: load range $-10 \mathrm{~N}$; extension-40 mm; gauge length $-30 \mathrm{~mm}$; approach speed $-5 \mathrm{~mm} / \mathrm{min}$; test speed $-50 \mathrm{~mm} / \mathrm{min}$; and a preload force $-0 \mathrm{~N}$. The tensile properties were calculated using the following equations.

$$
\begin{aligned}
& \text { Elastic modulus }\left(\frac{\mathrm{N}}{\mathrm{mm}^{2}}\right) \\
& =\frac{\text { Force corresponding strain }(\mathrm{N})}{\text { cross-sectional }\left(\mathrm{mm}^{2}\right) \times \text { corresponding strain }} \\
& \% \text { Elongation } \\
& =\frac{\text { Increase in length }(\mathrm{mm})}{\text { Orginal length of the sample }(\mathrm{mm})} \times 100 \\
& \text { Tensile strength }\left(\frac{\mathrm{N}}{\mathrm{mm}^{2}}\right) \\
& =\frac{\text { Force at break }(\mathrm{N})}{\text { Inital cross-sectional area of sample }\left(\mathrm{mm}^{2}\right)}
\end{aligned}
$$




\subsection{Thermal Analysis}

1) Hot stage microscopy (HSM)

Analyses were carried out using a Mettler Toledo HSM instrument (Leicester-UK). A small sample of starting materials or film was placed on a glass slide located in a furnace below the microscope lens. Samples were subjected to a dynamic heating cycle from 30 to $300^{\circ} \mathrm{C}$ at a rate of $10^{\circ} \mathrm{C} / \mathrm{min}$ and all phase transitions were recorded as a video file.

2) Thermogravimetric analysis (TGA)

TGA was used to determine the residual water in the films (Table 2) and the effect of plasticizer and ibuprofen concentration and storage on the moisture content of the films. About 3 - $10 \mathrm{mg}$ of sample was weighed, placed in aluminium pans $(100 \mu \mathrm{L})$ and weight loss determined using a high resolution TGA 2950 instrument (TA Instruments, Crawley, UK). The experimental program involved heating the samples from $25^{\circ} \mathrm{C}$ to $150^{\circ} \mathrm{C}$ at a heating rate of $10^{\circ} \mathrm{C} / \mathrm{min}$.

3) Differential scanning calorimetry (DSC)

DSC analysis of physical mixtures of the starting ma- terials and the optimized films was performed using a Q2000 instrument (TA Instruments, Crawley, UK). The instrument was calibrated with indium and sapphire before analyzing samples under a nitrogen atmosphere. $\mathrm{T}$ zero aluminium pans $(75 \mu \mathrm{L})$ were packed with $3-10$ $\mathrm{mg}$ of sample and hermetically sealed. The thermal cycle involved cooling the sample to $-80^{\circ} \mathrm{C}$ and maintaining this temperature for 5 minutes. The samples were then heated at a rate of $10^{\circ} \mathrm{C} / \mathrm{min}$ up to $180^{\circ} \mathrm{C}$, and kept at this temperature for 3 minutes to allow complete melting. The run proceeded with quench cooling of the sample at a rate of $-10^{\circ} \mathrm{C} / \mathrm{min}$ to return to a temperature of $-80^{\circ} \mathrm{C}$. This process was repeated twice to investigate the stability of carrageenan, PEG and ibuprofen during the heating cycle. Further experiments were performed based on the possible interaction between PEG 600 and poloxamer 407. This was due to an extra melting transition observed in the films' DSC thermogram. The two polymers were mixed in ratios corresponding to those present in the films and melted before loading into the $\mathrm{T}$ zero DSC pans. The analysis involved a heating cycle from $-80^{\circ} \mathrm{C}$

Table 2. Water content for different films produced during the formulation development and optimization process, containing various $\kappa$-carrageenan grades (911 \& 812), plasticizers (GLY or PEG 600) and poloxamer 407 with or without ibuprofen. The last two rows show the final optimised films containing $\kappa$-carrageenan 911 (CAR), PEG 600 and poloxamer 407 (POL) freshly prepared and ibuprofen (IBU) loaded equivalents either freshly prepared or stored for a month. The \% concentrations of the components refer to the amounts present in the original gels used to prepare the corresponding films.

\begin{tabular}{|c|c|c|c|c|}
\hline CAR $(\% \mathrm{w} / \mathrm{w})$ & POL $(\% \mathrm{w} / \mathrm{w})$ & Plasticizer (\% w/w) & IBU (\% w/w) & Water content $(\%)$ \\
\hline $2.5(812)$ & 4 & $5.0 \mathrm{GLY}$ & - & $16.4 \pm 0.8$ \\
\hline $2.5(911)$ & 4 & $5.0 \mathrm{GLY}$ & - & $6.9 \pm 0.4$ \\
\hline $2.5(812)$ & 4 & $5.0 \mathrm{GLY}$ & 0.3 & $19.9 \pm 1.1$ \\
\hline $2.5(911)$ & 4 & $5.0 \mathrm{GLY}$ & 0.3 & $23.5 \pm 1.2$ \\
\hline $2.5(812)$ & 4 & 5.0 PEG & - & $10.3 \pm 0.6$ \\
\hline $2.5(911)$ & 4 & 5.0 PEG & - & $2.3 \pm 0.3$ \\
\hline $2.5(812)$ & 4 & $5.0 \mathrm{GLY}$ & 0.3 & $17.1 \pm 0.7$ \\
\hline $2.5(911)$ & 4 & $5.0 \mathrm{GLY}$ & 0.3 & $13.9 \pm 0.8$ \\
\hline $2.5(812)$ & 4 & 5.0 PEG & 0.4 & $12.1 \pm 0.7$ \\
\hline $2.5(911)$ & 4 & 5.0 PEG & 0.4 & $3.7 \pm 0.2$ \\
\hline $2.5(812)$ & 4 & 5.0 PEG & 0.4 & $9.9 \pm 0.5$ \\
\hline $2.5(911)$ & 4 & 5.0 PEG & 0.4 & $8.1 \pm 0.4$ \\
\hline $2.5(911)$ & 4 & $5.5 \mathrm{GLY}$ & - & $23.5 \pm 1.2$ \\
\hline $2.5(911)$ & 4 & 5.5 PEG & - & $5.1 \pm 0.4$ \\
\hline $2.5(911)$ & 4 & 6.5 PEG & 0.8 & $5.1 \pm 0.1$ (freshly prepared film) \\
\hline $2.5(911)$ & 4 & 6.5 PEG & 0.8 & $1.0 \pm 0.3$ (after 6 month storage) \\
\hline
\end{tabular}


to $80^{\circ} \mathrm{C}$ at a rate of $10^{\circ} \mathrm{C} / \mathrm{min}$ followed by cooling at a rate of $-10^{\circ} \mathrm{C} / \mathrm{min}$ to $-80^{\circ} \mathrm{C}$, and the cycle repeated. To determine the detection limit of the instrument for ibuprofen in the films, the equivalent amount of the pure drug was loaded onto the DSC and analyzed as above.

\subsection{Scanning Electron Microscopy (SEM)}

SEM was used to examine the surface of the films to determine their microscopic morphology. Samples were uncoated and tested using a JEOL instrument (Japan) by a back scattered electron technique with the aid of artificial shadowing in low vacuum $(20 \mathrm{~Pa})$ and an accelerating voltage of $20 \mathrm{kV}$.

\subsection{X-Ray Powder Diffraction (XRPD)}

X-ray diffraction patterns were recorded and used to determine the physical form (crystalline or amorphous) of the individual components present in the film. A D8 Advance XRPD diffractmeter (Bruker, Coventry, UK) which was equipped with a Lyn $\mathrm{X}$-Iris detector and 6.5 $\mathrm{mm}$ slit size was employed to obtain results in reflection and transmission modes. The X-ray instrument was set at $40 \mathrm{kV}$ and $40 \mathrm{~mA}$ with primary solar slit of $4^{\circ}$ and a secondary solar slit of $2.5 \mathrm{~mm}$ while the scattered slit was $0.6 \mathrm{~mm}$. Samples were scanned at a speed of $0.02^{\circ}$, 2 -theta step size every 0.1 seconds. The same was conducted for pure PEG 600, poloxamer 407 and their physical mixtures before and after heating on the DSC.

\subsection{Stability Test}

The formulations wrapped in paraffin film (to prevent moisture absorption by $\kappa$-carrageenan 911 , which is hygroscopic) were stored at room temperature and $45 \%$ relative humidity $(\mathrm{RH})$ over a six month period and the drug content assayed monthly using HPLC. A standard solution of ibuprofen $(0.05 \mathrm{mg} / \mathrm{ml})$ was used to develop a suitable HPLC method. Different ratios of organic solvents (methanol, acetonitrile) and the aqueous phase (acetic acid, ortho-phosphoric acid) were investigated to determine the optimum $\lambda_{\max }$. Based on the results the final HPLC parameters were selected as follows: ODS C18 reverse phase $5 \mu \mathrm{m}$ particle size column (Hichrom H50DS-3814), mobile phase methanol: water: orthophosphoric acid (74:24:2), flow rate $1.5 \mathrm{~mL} / \mathrm{min}$ and diode array UV detection at $214 \mathrm{~nm}$. A $0.5 \mathrm{mg} / \mathrm{ml} \mathrm{stan-}$ dard solution of ibuprofen was prepared, serially diluted $(0.05,0.075,0.1,0.125$ and $0.15 \mathrm{mg} / \mathrm{ml})$ and analyzed by HPLC and the data used to plot a calibration curve. Drug stability over the storage period was analyzed by dissolving films in deionized water prior to running on the HPLC. Pure crystalline ibuprofen powder stored at room temperature as for the films was used as a control.

\subsection{Drug Dissolution and Release Profile Studies}

Before performing dissolution studies, the amount of ibuprofen present within the film was assayed by HPLC using the same conditions as for the stability studies. Dissolution studies were performed using two different dissolution media: 1) deionized water, $\mathrm{pH}$ of 5.6 as a control, and 2) buffer solution $\left(100 \mathrm{ml}\right.$ of $\mathrm{KH}_{2} \mathrm{SO}_{4}(0.1 \mathrm{M})$ plus $13 \mathrm{ml}$ of $\mathrm{NaOH}(0.1 \mathrm{M})$ with $\mathrm{pH}$ of 6.2 to simulate that of saliva. As a further control, two $15 \mathrm{mg}$ samples of pure crystalline ibuprofen were weighed and dispersed separately in $50 \mathrm{~mL}$ buffer solution and $50 \mathrm{ml}$ deionized water, respectively, at room temperature with continuous stirring and the same procedure repeated as for the films. Dissolution media were sampled at 5 minute intervals starting from time zero till two hours and absorbance (214 nm) measured using a Varian Spectro-photometer (Yarnton, UK). Cumulative amounts of drug released (mg) were calculated from the calibration curve and the percentage drug release versus time profiles plotted. The kinetics of ibuprofen release from the films were evaluated by determining the best fit of the dissolution data (percentage release vs. time) to the Higuchi, KorsmeyerPeppas, zero order and first order equations.

\section{Results and Discussion}

\subsection{Formulation Development}

The initial stages in the formulation of the films involved polymer swelling, hydration and subsequent formation of uniform and easily flowing gels for drying. $\kappa$-carrageenan 911 formed a firm gel which produced a flexible film in the presence of PEG 600 while the $\kappa$-carrageenan 812 gel was strong; hence the resulting film was very brittle even after the addition of plasticizer. Therefore, $\kappa$-carrageenan 911 was the polymer of choice for further studies. However, complete hydration and production of a uniform gel was challenging due to its high molecular weight and was also dependent on the temperature. One means of overcoming this challenge was by prolonging the hydration and swelling time of carrageenan 911 in aqueous solution to 24 hours, which allowed complete hydration at a lower temperature $\left(40^{\circ} \mathrm{C}-50^{\circ} \mathrm{C}\right)$. However, this approach was very time consuming. The alternative approach for obtaining films with acceptable characteristics, involved dissolving poloxamer 407 in water for two hours before addition of carrageenan. This gel formation approach was used in all subsequent experiments for investigating maximum drug loading.

The characteristics of an "ideal" film were evaluated based on criteria such as transparency and homogeneity (i.e. transparent without any entrapped air bubbles or patches), plasticity (non-brittle films) and thickness (less 
than 1mm) [19] Based on the foregoing criteria, only $\kappa$-carrageenan 911 produced films with acceptable characteristics. Although glycerol plasticized films containing no drug showed ideal characteristics of transparency and thickness less than $1 \mathrm{~mm}$, the corresponding ibuprofen loaded films did not exhibit the other desirable physical characteristics described above as the films showed a patchy and uneven distribution of the various components on the surface, resulting in an opaque appearance (Figure 2(a)). This could be due to the higher amounts of water retained by glycerol containing films, compared to PEG (Table 2). As a result, glycerol was discontinued as a plasticizer in drug loaded films. On the other hand, PEG 600 (Figure 2(b)) at an optimum percentage (5.5\% - $6.5 \% \mathrm{w} / \mathrm{w}$ ) within the gel produced flexible films with sufficient rigidity and toughness under stress and during handling and was therefore the plasticizer of choice for all subsequent formulations.

The optimum concentrations of $\kappa$-carrageenan 911 and poloxamer 407 within the gel were determined to be $2.5 \%$ and $4 \% \mathrm{w} / \mathrm{w}$ respectively. The maximum concentration of ibuprofen that could be incorporated into the gel was $0.8 \% \mathrm{w} / \mathrm{w}$. This was achievable at a PEG 600 concentration of $6.5 \% \mathrm{w} / \mathrm{w}$ in the gel preparation using the second drug loading approach, by initially dissolving ibuprofen in ethanol. In addition, there was no significant weight variation after an optimum drying time of 24 hours.

\subsection{Texture Analysis}

Texture analysis was used to measure tensile properties, tensile strength (brittleness of films), elastic modulus (rigidity) and elongation (flexibility and elasticity). The elastic modulus was estimated from the initial linear portion of the stress-strain curve (Equation (1)) whilst tensile strength was calculated by dividing force at break by

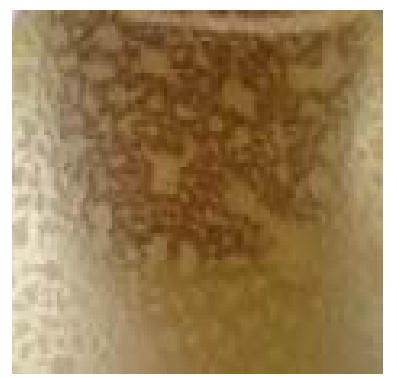

(a)

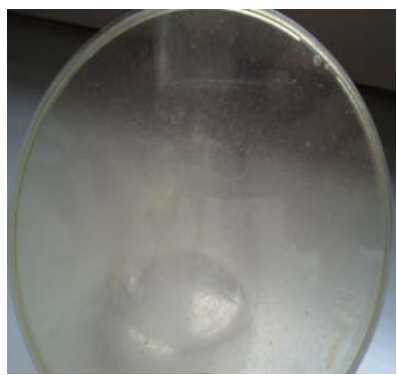

(b)
Figure 2. Digital images of ibuprofen loaded films plasticized with (a) glycerol showing a non-uniform film with patches of accumulated initial material and (b) PEG 600 which appears clear, transparent and exhibited acceptable flexibility. the initial cross-sectional area of the films specimen. Figure 3(a) shows that the elastic modulus decreases gradually with increasing PEG 600 concentration for films containing no ibuprofen. According to the results, the concentration of $5.5 \% \mathrm{w} / \mathrm{w}$ PEG 600 in gel (corresponding to a $\kappa$-carrageenan $911 / \mathrm{PEG} 600$ ratio of 5:11) resulted in the elastic modulus reaching the minimum value while the percent elongation remained at the maximum.

Increasing the PEG 600 concentration to $6.5 \% \mathrm{w} / \mathrm{w}$ resulted in a significant decrease in the percentage elongation and a corresponding increase in the elastic modu- lus of the blank (non-drug loaded) films. However, different observations were made when ibuprofen was present. Following the addition of ibuprofen, the elastic modulus

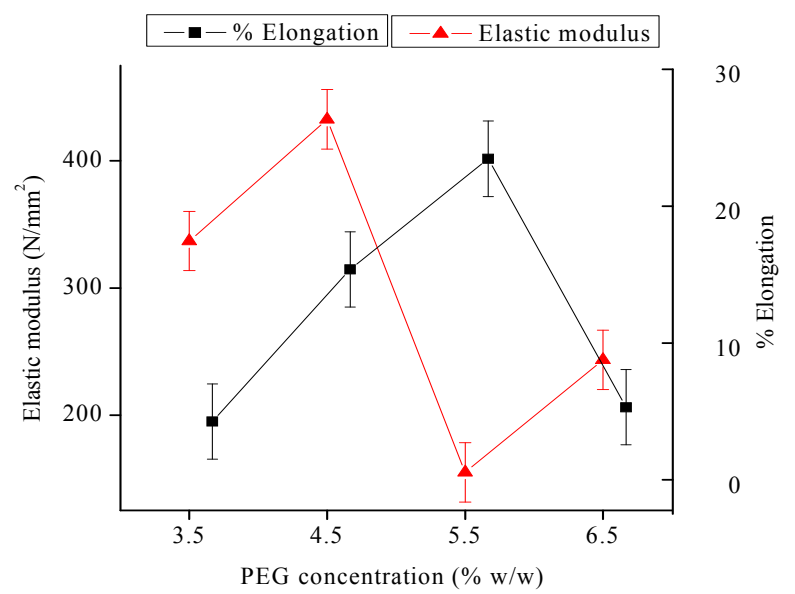

(a)

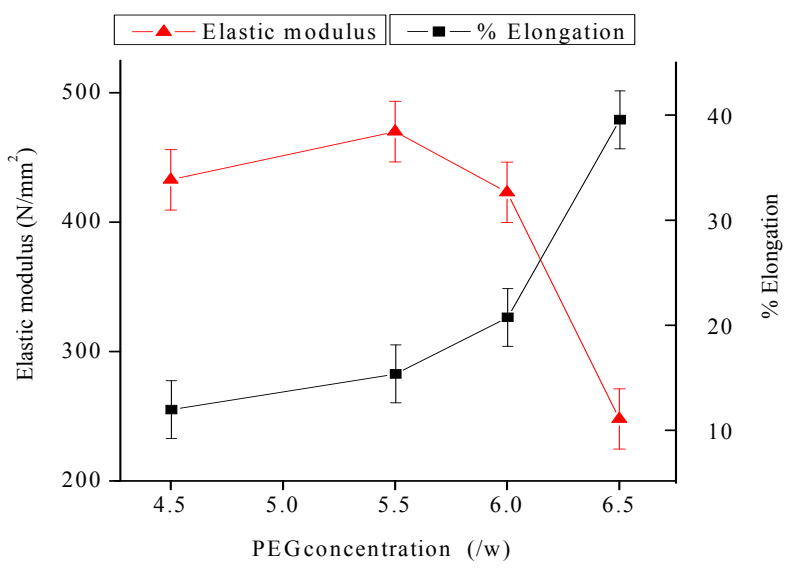

(b)

Figure 3. Tensile results from texture analyses showing the variations in elastic modulus and percentage elongation of films with increasing concentration of PEG 600 for (a) optimized films containing no drug and (b) optimized films prepared from gels containing $0.8 \% \mathrm{w} / \mathrm{w}$ ibuprofen. 
values measured were higher than for the blank film and required an increase in PEG 600 content to $6.5 \% \mathrm{w} / \mathrm{w}$ to obtain films with desirable flexibility and toughness.

This increased concentration of PEG 600 allowed the maximum $0.8 \% \mathrm{w} / \mathrm{w}$ ibuprofen loading in the gel, whilst maintaining desirable film flexibility matching that of the non-drug loaded films (Figure 3(b)). The tensile strength, elongation and elastic modulus values are relevant as they indicate the strength of the film under stress due to stretching and have a direct effect on patient's acceptance and clinical performance of the final dosage form. Flexible films provide better patient compliance as they are less likely to cause contact irritation. However, an unduly elastic film is likely to cause problems with handling such as folding and stickiness [19].

\subsection{Thermal Analysis}

1) Hot stage microscopy (HSM)

HSM results specified the degradation point for the film samples loaded, which was about $190^{\circ} \mathrm{C}$. These results helped in developing suitable methods for TGA and DSC analyses and determined the maximum temperature to which samples could be heated.

2) Thermo gravimetric analysis (TGA)

TGA evaluation showed that the residual water in the non-drug loaded films plasticized with glycerol was considerably higher than films plasticized with PEG 600 (Table 2). This was attributed to the fact that glycerol which is a known moisturizing agent retained more water in the film matrix than PEG 600 owing to its higher affinity for water. Whilst this was not an issue with the current model drug (ibuprofen), it could cause instability especially for water sensitive drugs [20]. In the case of films containing ibuprofen plasticized with PEG, the residual (free) water content was considerably lower compared to non-drug loaded films after storage for six months due to loss in water during storage.

3) Differential scanning calorimetry (DSC)

To be able to evaluate the behavior of ibuprofen within the films, based on its phase transition profiles, preliminary experiments of the pure compounds were conducted. The results (Figures 4(a) and (b)) were used as the reference glass transition temperature and melting points of the amorphous and crystalline forms of ibuprofen, respectively. Figure 4(a) shows the glass transition of the pure ibuprofen in amorphous form at a temperature of $-45.27^{\circ} \mathrm{C}$ and Figure 4(b) shows the melting temperature of the crystalline form at $77.68^{\circ} \mathrm{C}$. Results of the characterization of the thermodynamic behavior of films formulated with carrageenan 911, poloxamer 407, PEG 600 and ibuprofen by DSC confirmed the absence of the sharp melting point of the crystalline form of ibuprofen at $77.68^{\circ} \mathrm{C}$. Instead the glass transition $\left(\mathrm{T}_{\mathrm{g}}\right)$ corresponding to the amorphous form of ibuprofen was detected at

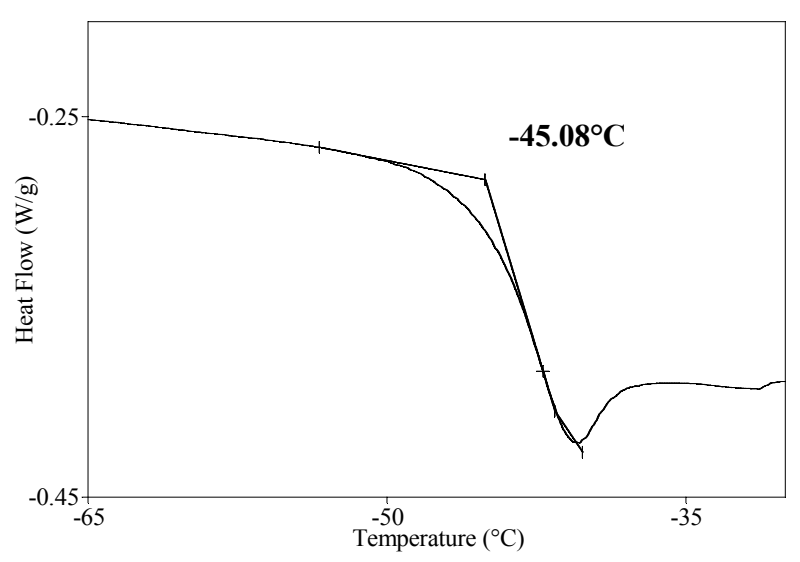

(a)

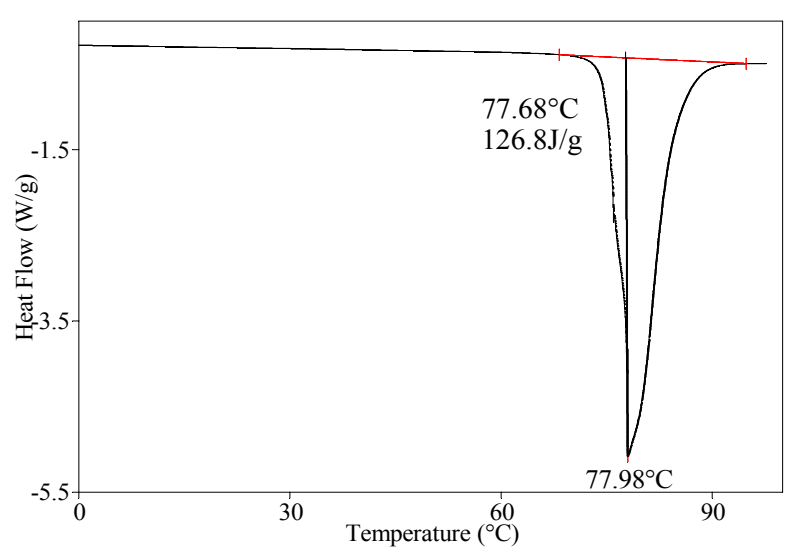

(b)

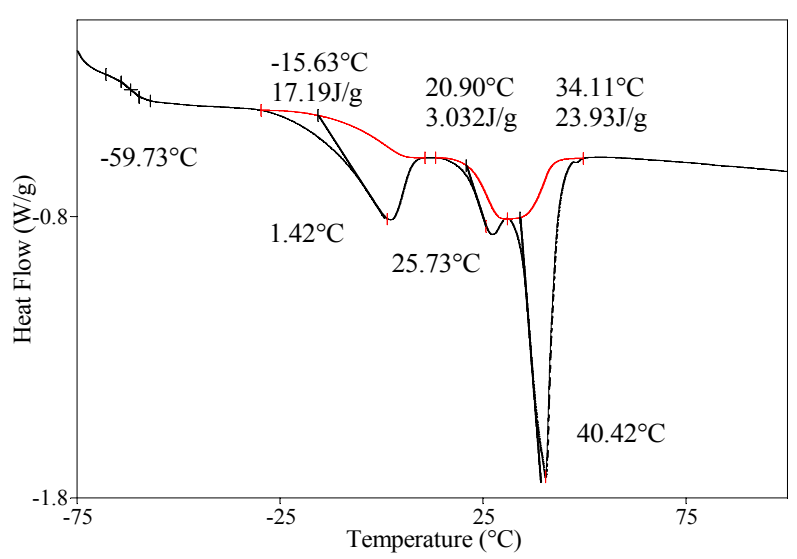

(c)

Figure 4. DSC profiles showing (a) glass transition of pure amorphous ibuprofen; (b) melting point of pure crystalline ibuprofen and (c) phase transitions of the film containing ibuprofen. 
$-59.73^{\circ} \mathrm{C}$ (Figure 4(c)). It has been reported [21] that the reason for the variation in glass transition point value is the existence of plasticizer in the system which results in the depression of the $\mathrm{T}_{\mathrm{g}}$. The results suggest that ibuprofen was present within the film matrix in an amorphous form and was converted from the crystalline form originnally added to the gel. Though amorphous forms are known to be more soluble, they do present stability challenges owing to their tendency to convert back to the crystalline form [22-24].

To investigate the stability of ibuprofen within the films, further DSC experiments were conducted to determine whether ibuprofen remained in an amorphous form or was converted back to the crystalline form during storage. The DSC results confirmed that ibuprofen remained in the amorphous form within the film after storage at room temperature for six months (Figure 5).

The results from mixing PEG 600 and poloxamer 407 [in the same ratio (56:34) as present in the film respecttively] showed another melting transition which appeared between the transitions for PEG 600 and poloxamer (Figure 6(a)). This is the reason for the DSC profile of the film exhibiting three melting transitions instead of two, corresponding to PEG 600 and poloxamer 407 (Figure 4(c)). It is plausible therefore that a mixture of poloxamer and PEG 600 is formed within the film which has a direct modifying effect on the melting point of each compound as well. Instead of two melting points, three melting peaks, representing the melting point of PEG 600, poloxamer 407 and the mixture was detected in films between $20^{\circ} \mathrm{C}-25^{\circ} \mathrm{C}$. There are two possible reasons with regards to the identity of the mixture.

1) The first hypothesis is that poloxamer 407 solubilizes

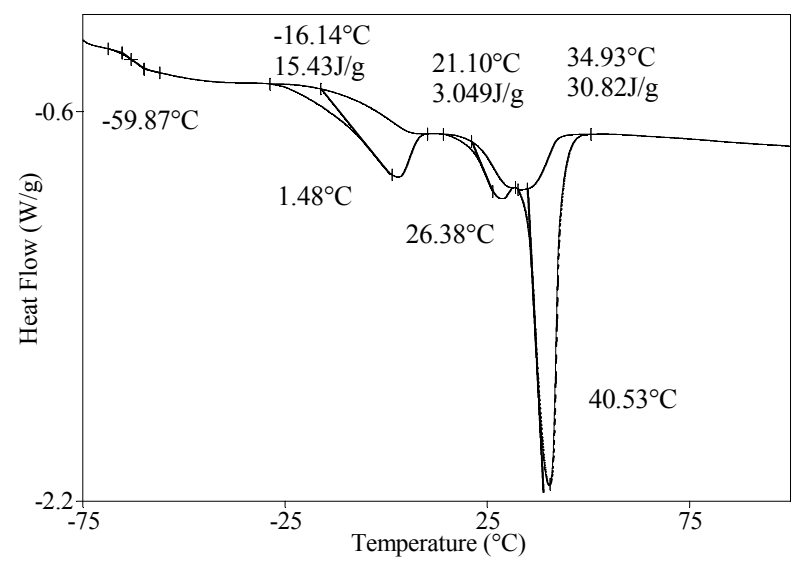

Figure 5. DSC profile of film containing ibuprofen after 6 month storage under room temperature conditions showing three separate transitions attributed to poloxamer 407, PEG 600 and the new entity comprising a mixture of both compounds. in the PEG 600 which could result in micelles of poloxamer 407 in the core surrounded by PEG 600 in the shell. However, comparison of XRPD diffractogram (Figure 6(b)) for pure PEG 600 and poloxamer 407 and their mixtures before and after heating by DSC demonstrates that this hypothesis is unlikely to occur as the only crystalline form present in the system was poloxamer 407. Furthermore, the DSC results and the above hypothesis relate to the non-drug loaded films but not the physical mixtures or ibuprofen loaded films and therefore cannot account for the incorporation of ibuprofen within such micelles.

Although a shift in the melting transition of poloxamer and PEG 600 was observed, it did not have any effect on the thermal characteristics of ibuprofen. Therefore it can be concluded that ibuprofen was not incorporated in micelles comprising PEG and poloxamer.

2) The chemical structure of poloxamer 407 shows that it comprises 79\% PEG and 21\% PPG (polypropylene oxide). PEG has the ability to form inter-chain hydrogen bonding as well as hydrogen bonding with water. It is therefore possible that the presence of water may promote greater interaction of the PEG chains of poloxamer 407 and PEG 600 through greater hydrogen bonding. The removal of water may weaken this interaction leading to the formation of two distinct peaks during storage.

\subsection{X-Ray Powder Diffraction (XRPD)}

Figure 6(b) shows the XRPD spectra for physical mixtures of PEG 600 and poloxamer 407 as was analyzed on the DSC. The spectra confirm the formation of a single entity representing a mixture of poloxamer 407 and PEG 600 within the film. Figure 7 shows the XRPD spectra of films containing ibuprofen. Figure 7(a) corresponds to the film containing all components (carrageenan 911, poloxamer 407, PEG 600 and ibuprofen). Since carrageenan 911, which is in amorphous form, was present in a relatively high proportion within the film, a broad XRPD spectrum was obtained. To eliminate this effect, the spectra for carrageenan 911 were background subtracted. The resulting spectrum represents all the crystalline molecules present within the film matrix. The results demonstrate the absence of the main peak of crystalline ibuprofen that should have appeared at 16.2 (2-theta) according to the XRPD library data base. This confirmed the DSC results and showed that the initial crystalline ibuprofen originally added to the system was transformed into amorphous form during film formation. The data in Figure 7(b) shows that the relative percentage of PEG 600 changed during storage with an increase in the ratio of crystalline to amorphous content as a consequence of re-crystallization of PEG 600, with a resultant change in 


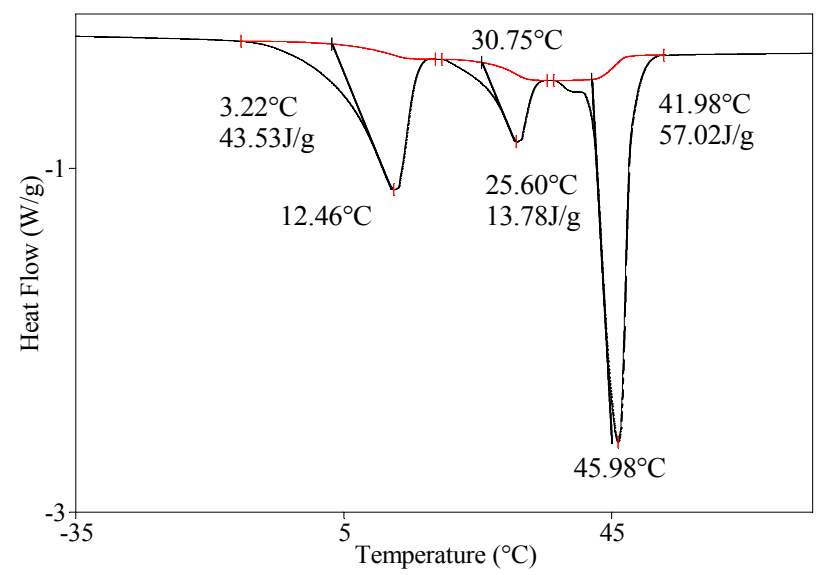

(a)

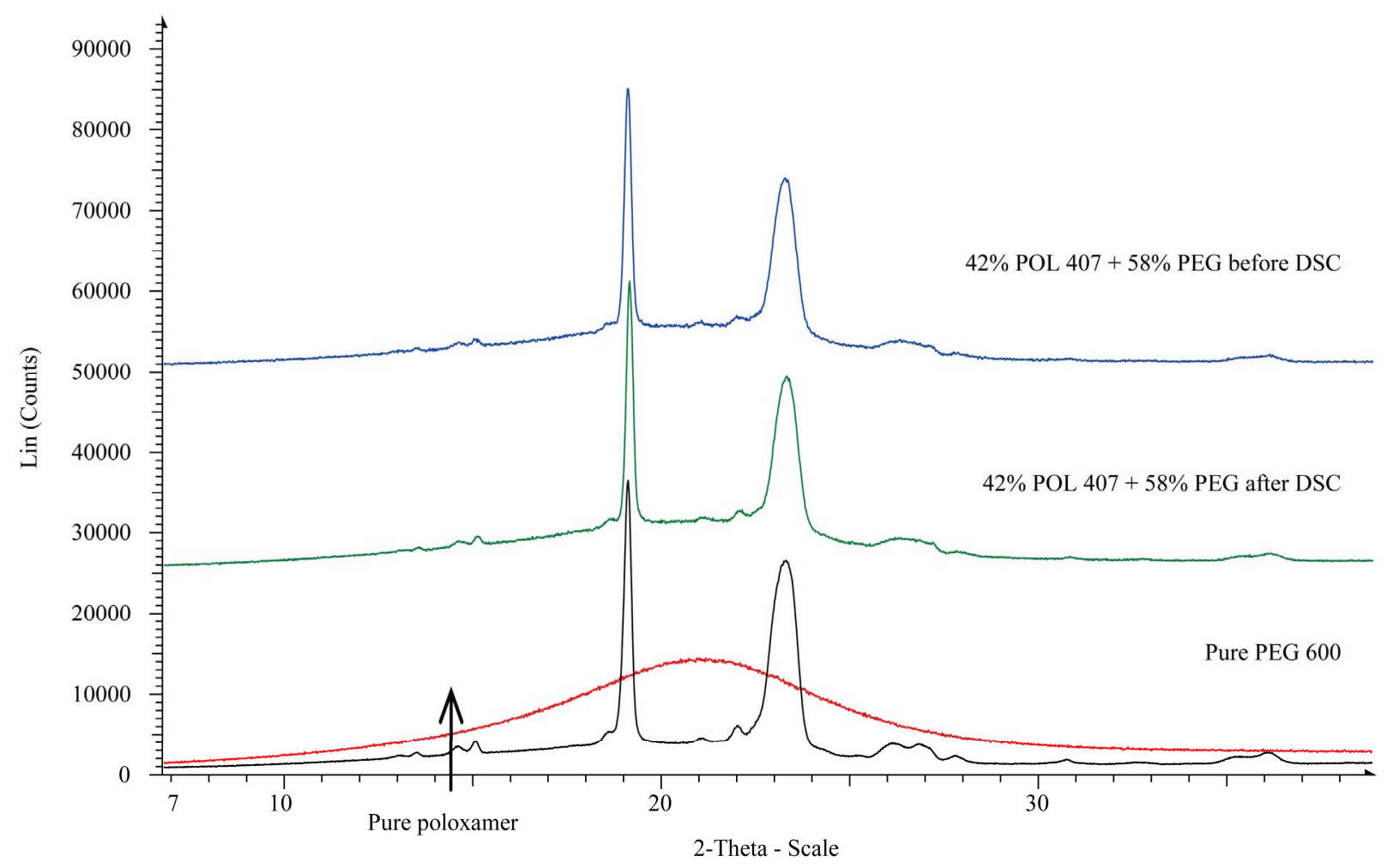

(b)

Figure 6. (a) DSC results for the physical mixture of PEG 600 and poloxamer 407 during second heating cycle showing the new melting point transition appearing between the two melting points of the individual components and (b) corresponding XRPD diffractograms showing the spectra of the starting materials and physical mixtures.

the XRPD profile. However, amorphous ibuprofen did not present any significant instability by way of recrystallization back to the crystalline form during six months of storage.

\subsection{Scanning Electron Microscopy (SEM)}

SEM was used to evaluate the surface characteristics (morphology) of the films and how that could impart other physico-chemical properties. The microscopic appearance of the film surface showed continuous sheet which was also uniform with no obvious porous regions (Figure 8(a)) and was maintained after incorporation of ibuprofen (Figure 8(b)). This is important because the rates of hydration, swelling and eventual drug dissolution 


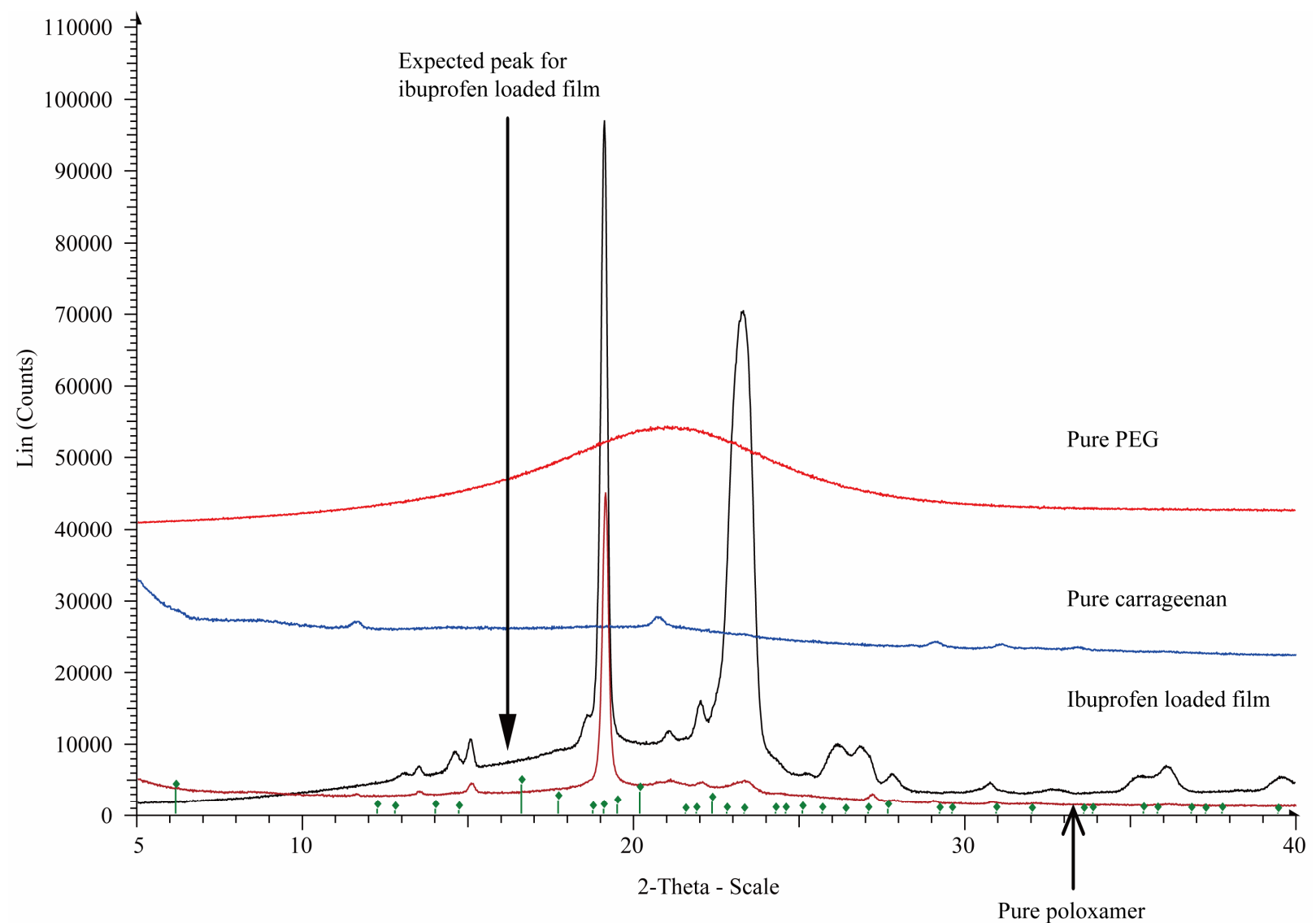

(a)

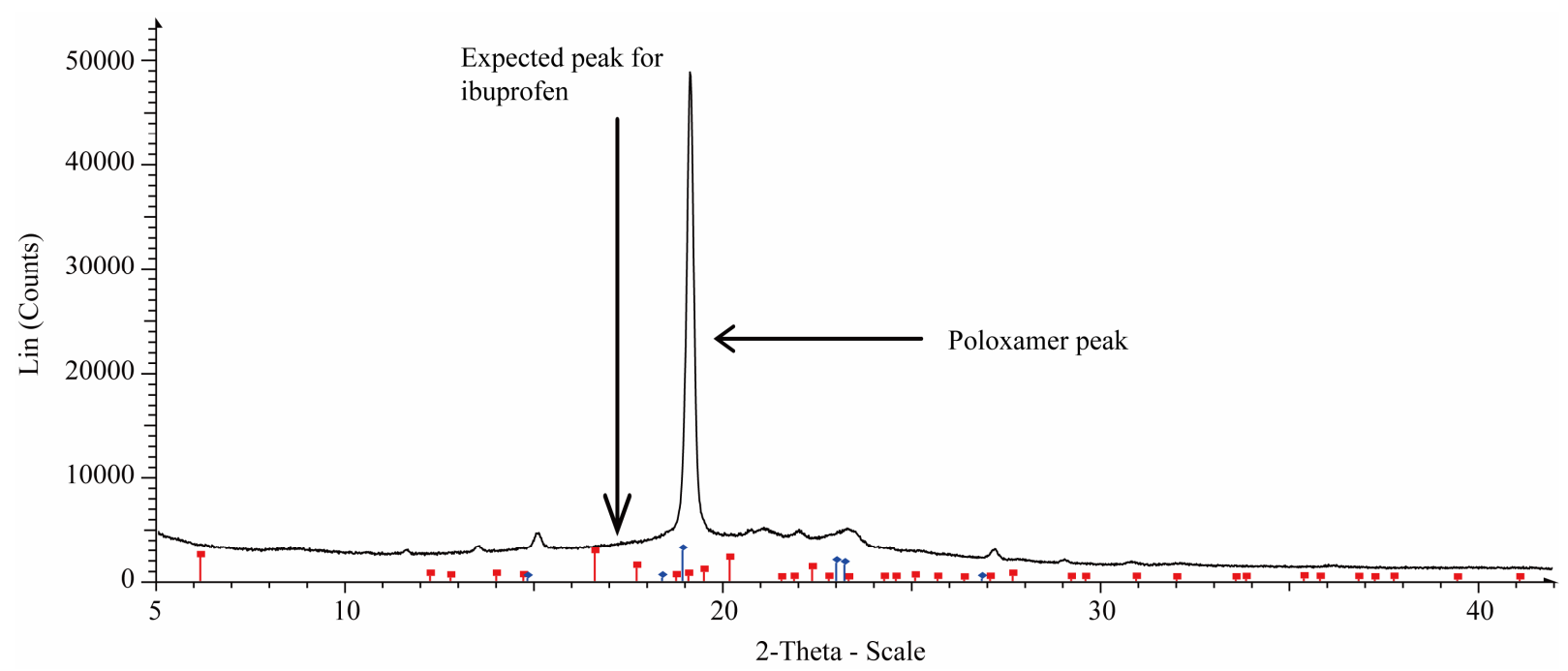

(b)

Figure 7. XRPD profiles of (a) combined diffractograms of $\kappa$-carrageenan 911, poloxamer 407 and PEG 600 film's showing the absence of expected ibuprofen peak in the freshly prepared drug loaded film and (b) diffract gram for ibuprofen loaded film after 1 month storage at room temperature conditions showing sharp crystalline peak of PEG 600 and absence of ibuprofen crystalline peak. 


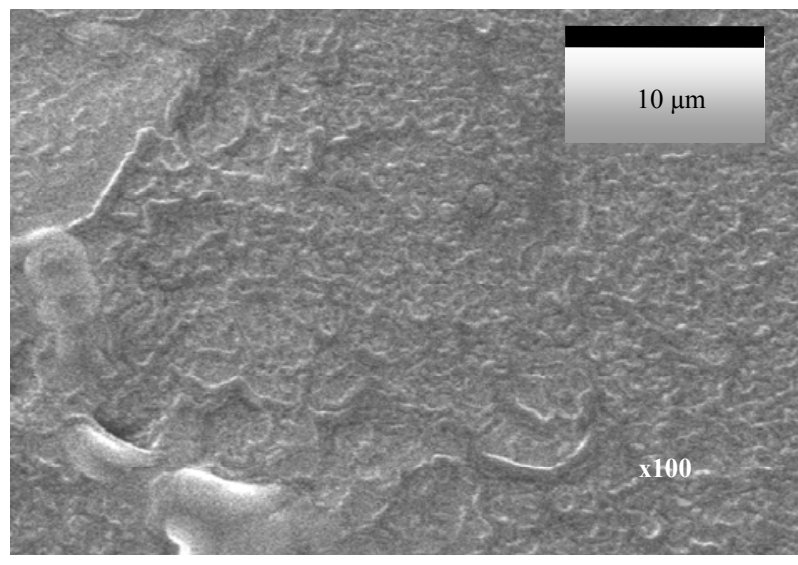

(a)

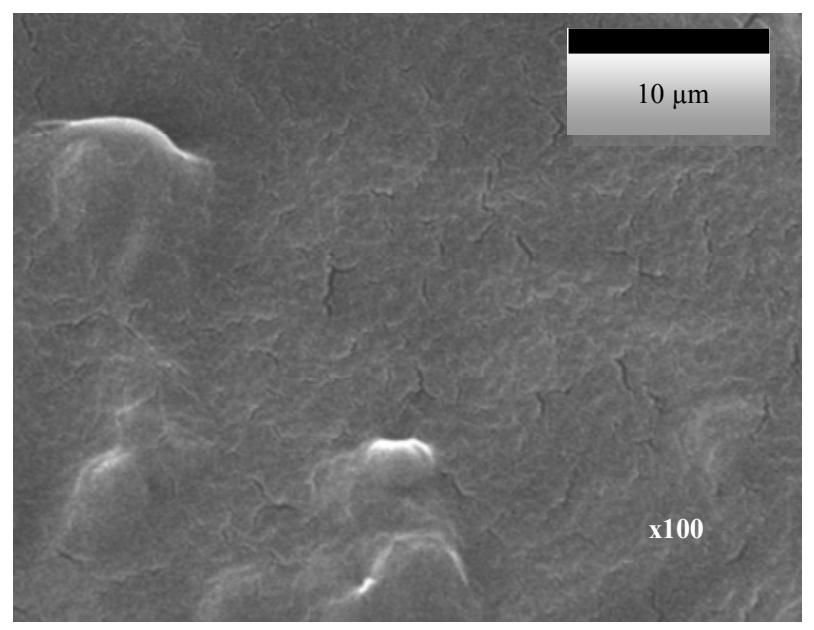

(b)

Figure 8. SEM images $(\times 100$ magnification) showing the surface morphology of films prepared from carrageenan 911, poloxamer 407 and PEG 600 (a) containing no ibuprofen and (b) that loaded with ibuprofen.

are dependent on the physical integrity of the film structure as it affects the initial rate of water ingress [6]. It also shows a uniform distribution of the drug within the film matrix which is highly desirable, in order to prevent potential re-crystallization and crystal growth, which could lead to instability.

\subsection{Stability Studies}

HPLC results showed that the actual concentration of ibuprofen in the film sample did not change significantly after six month storage at room temperature and $45 \% \mathrm{RH}$ ( $>90 \%$ assay). The pure crystalline ibuprofen used as control also remained stable over 6 months. Though this is highly desirable, longer term stability of ibuprofen within the films will need to be studied under accelerated conditions of higher temperature and relative humidity
[25] demonstrated that the degradation of ibuprofen in bulk-drug samples ranged between $2.9 \%$ and $11.4 \%$ following storage at the higher temperature of $80^{\circ} \mathrm{C}$. Ibuprofen degradation under high temperature conditions is likely given the alcohol functions present which could result in possible ester formation between PEG 600 and ibuprofen [26] have shown previously that polyethylene glycol enhances the degradation of ibuprofen in tablets under accelerated conditions of $70^{\circ} \mathrm{C}$ and $75 \% \mathrm{RH}$ and such studies will be required to confirm this in the films.

\subsection{Drug Dissolution and Release Profiles}

The data in Figure 9 compares the dissolution profiles for pure crystalline ibuprofen (control) and that within the films using the two different dissolution media (deionised water and buffer). Pure ibuprofen initially dissolved relatively quickly due possibly to the immediate contact with the dissolution medium but reached a plateau in 10 minutes. In contrast, ibuprofen was initially released from the film matrix more quickly but showed constant release profiles overall, reaching $65 \%$ and $58 \%$ in 120 minutes for buffer and deionised water, respectively. The dissolution profiles and gradient derived from the initial linear portion of the drug release vs. time curves confirmed the effect of $\mathrm{pH}$ on drug release rate from the film matrix. These results showed that the rate of drug release was accelerated in the simulated saliva $\mathrm{pH}$ environment compared with the acidic $\mathrm{pH}$ condition (deionized water). In addition, the maximum drug release in buffer solution was about $8 \%$ higher than in acidic $\mathrm{pH}$ (corresponding to stomach dissolution media). This presents a potential advantage of buccal delivery over the traditional oral route. This is an interesting finding for films intended for buccal mucosa applications. However, this needs further investigations as the difference observed could relate to ionization suppression of the acidic ibuprofen at the lower $\mathrm{pH}$ of deionised water.

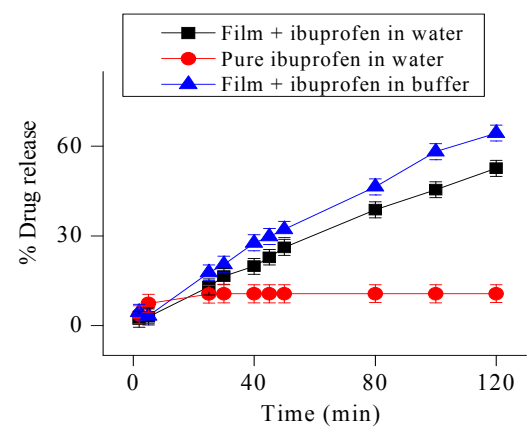

Figure 9. Comparison of the dissolution profiles of pure crystalline ibuprofen, and that contained within the film in water and buffer dissolution media which simulated that of saliva. 
These results indicate that ibuprofen was present in the films in the amorphous form as compared to the pure crystalline form used as a control. The amorphous form of the drug being more water soluble is expected to have a higher rate of dissolution according to Noyes-Whitney equation and therefore may account for the higher rates of release via diffusion and swelling of the polymer matrix.

Dissolution data were fitted to different kinetic models and the $\mathrm{R}^{2}$ values for the four models were calculated as Higuchi $\left(\mathrm{R}^{2}=0.98\right)$, Korsmeyer-Peppas $\left(\mathrm{R}^{2}=0.98, \mathrm{n}=\right.$ $1.1)$, zero order $\left(R^{2}=0.99\right)$ and first order $\left(R^{2}=0.98\right)$ which were not significantly different [27]. The Peppas equation $\left(\mathrm{Q}=\mathrm{kt}^{\mathrm{n}}\right)$ is generally used to analyze the release of pharmaceutical polymeric dosage forms when the release mechanism is not well known (anomalous transport release). It is also useful when more than one type of release phenomenon could be involved, for example, swelling and erosion of polymer. The equation becomes more realistic in two main cases; pure diffusion controlled drug release, $\mathrm{n}=0.5$ and swelling controlled drug release, $n=1$ (Case II transport). Other values of $n$ indicate anomalous transport kinetics i.e. a combined mechanism of pure diffusion and swelling and the magnitude of $\mathrm{n}$ can be used as an indication of the type of transport mechanism for the drug. A value of $\mathrm{n} \leq 0.45$ corresponds to Fickian diffusion release (case I diffusional), $(0.45<\mathrm{n}$ $\leq 0.89$ ) to an anomalous (non-Fickian diffusion) transport i.e. a gel erosion release mechanism, $\mathrm{n}=0.89$ to a zero-order (case II) release kinetics, and $\mathrm{n}>0.89$ to a super case II transport [28]. In the current study, the value of $\mathrm{n}$ was found to be 1.1, indicating super case II transport for drug release from the carrageenan based films.

\section{Conclusions}

Optimized buccal films with ideal flexibility and toughness were obtained from the gel comprising $2.5 \% \mathrm{w} / \mathrm{w}$ $\kappa$-carrageenan 911 in combination with $4 \% \mathrm{w} / \mathrm{w}$ poloxamer 407, 6.5\% w/w PEG 600 and $0.8 \% \mathrm{w} / \mathrm{w}$ ibuprofen. Thermal analysis showed that an interaction occurred between PEG 600 and poloxamer 407 and such interactions were dependent on the ratio of the two components within the film. The key finding of this study lies in the fact that ibuprofen, originally added as a crystalline polymorph, was converted into a stable amorphous form during film formation and this has an impact on the drug release profiles from the film matrix in dissolution medium simulating the $\mathrm{pH}$ of saliva. These films have potential for buccal drug delivery and will be investigated further for drug release and transport across ex vivo buccal membrane in subsequent studies.

\section{Acknowledgements}

The authors will like to thank BASF (Surrey, UK) for donating all grades of carrageenan used in this study.

\section{REFERENCES}

[1] A. Liekweg, M. Westfeld and U. Jaehde, "From Oncology Pharmacy to Pharmaceutical Care: New Contributions to Multidisciplinary Cancer Care," Supplementary Care in Cancer, Vol. 12, No. 2, 2004, pp. 73-79. doi:10.1007/s00520-003-0539-4

[2] M. Werle, A. Makhlof and H. Takeuchi, "Oral Protein Delivery: A Patent Review of Academic and Industrial Approaches," Recent Patent in Drug Delivery Formulations, Vol. 3, No. 2, 2009, pp. 94-104. doi: $10.2174 / 187221109788452221$

[3] D. K. Pettit and W. R. Gombotz, "The Development of Site-Specific Drug-Delivery Systems for Protein and Peptide Biopharmaceuticals," Trends in Biotechnology, Vol. 16, No. 8, 1998, pp. 343-349. doi:10.1016/S0167-7799(98)01186-X

[4] J. K. Oh, R. Drumright, D. Siegwart and K. Matyjaszewski, "The Development of Microgels/Nanogels for Drug Delivery Applications," Progress in Polymer Science, Vol. 33, No. 4, 2008, pp. 448-477. doi:10.1016/j.progpolymsci.2008.01.002

[5] K. K. Peh and C. F. Wong, "Polymeric Films as Vehicle for Buccal Delivery: Swelling, Mechanical, and Bioadhesive Properties," Journal of Pharmacy and Pharmaceutical Science, Vol. 2, 1999, pp. 53-61.

[6] J. S. Boateng, A. D. Auffret, K. H. Matthews, M. J. Humphrey, H. N. E. Stevens and G. M. Eccleston, "Characterization of Freeze-Dried Wafers and Solvent Evaporated Films as Potential Drug Delivery Systems to Mucosal Surfaces," International Journal of Pharmaceutics, Vol. 389, No. 1-2, 2010, pp. 24-31. doi:10.1016/j.ijpharm.2010.01.008

[7] N. Salamat-Miller, M. Chittchang and T. P. Johnston, "The Use of Mucoadhesive Polymers in Buccal Drug Delivery," Advanced Drug Delivery Reviews, Vol. 57, No. 11, 2005, pp. 1666-1691. doi:10.1016/i.addr.2005.07.003

[8] S. I. Pather, M. J. Rathbone and S. Senel, "Current Status and the Future of Buccal Drug Delivery Systems," Expert Opinions in Drug Delivery, Vol. 5, No. 5, 2008, pp. 531542. doi:10.1517/17425247.5.5.531

[9] B. Baert, E. Deconinck, M. Van Gele, M. Slodicka, P. Stoppie, S. Bodé, G. Slegers, Y. Vander Heyden, J. Lambert, J. Beetens and B. De Spiegeleer, "Transdermal Penetration Behavior of Drugs: CART-Clustering, QSPR and Selection of Model Compounds," Bioorganic Medicinal Chemistry, Vol. 15, No. 22, 2007, pp. 6943-6455. doi:10.1016/j.bmc.2007.07.050

[10] Y. Yuguchi, T. Thuy, H. Urakawa and K. Kajiwara, "Structural Characteristics of Carrageenan Gels: Temperature and Concentration Dependence," Food Hydro- 
colloids, Vol. 16, No. 6, 2002, pp. 515-522. doi:10.1016/S0268-005X(01)00131-X

[11] O. Tari, S. Kara and O. Pekcan, "Critical Exponents of Kappa Carrageenan in the Coil-Helix and Helix-Coil Hysteresis Loops," Journal of Macromolecular Science Part B-Physics, Vol. 48, No. 4, 2009, pp. 812-822. doi:10.1080/00222340902956129

[12] M. Thommes and P. Kleinebudde, "Use of Kappa-Carrageenan as Alternative Pelletisation Aid to Microcrystalline Cellulose in Extrusion/Spheronization. II. Influence of Drug and Filler Type," European Journal of Pharmaceutics and Biopharmaceutics, Vol. 63, No. 1, 2006. pp. 68-75. doi:10.1016/j.ejpb.2005.10.003

[13] Y. Liu, W. L. Lu, H. C. Wang, X. Zhang, H. Zhang, X. Q. Wang, T. Y. Zhou and Q. Zhang, "Controlled Delivery of Recombinant Hirudin Based on Thermo-Sensitive Pluronic (R) F127 Hydrogel for Subcutaneous Administration: In Vitro and in Vivo Characterization," Journal of Controlled Release, Vol. 117, No. 3, 2007, pp. 387-395. doi:10.1016/j.jconrel.2006.11.024

[14] A. Paavola, J. Yliruusi and P. Rosenberg, "Controlled Release and Dura Mater Permeability of Lidocaine and Ibuprofen from Injectable Poloxamer-Based Gels," Journal of Controlled Release, Vol. 52, No. 1-2, 1998, pp. 169-178. doi:10.1016/S0168-3659(97)00206-X

[15] G. G. Z. Zhang, D. Law, E. A. Schmitt and Y. H. Qiu, "Phase Transformation Considerations during Process Development and Manufacture of Solid Oral Dosage Forms," Advanced Drug Delivery Reviews, Vol. 56, No. 3, 2004, pp. 371-390. doi:10.1016/j.addr.2003.10.009

[16] F. Tirnaksiz and J. R. Robinson, "Rheological, Mucoadhesive and Release Properties of Pluronic F-127 Gel and Pluronic F-127/Polycarbophil Mixed Gel Systems," Pharmazie, Vol. 60, No. 7, 2005, pp. 518-523.

[17] H. Sohi, A. Ahuja, F. Jalees Ahmad and R. Krishen Khar, "Critical Evaluation of Permeation Enhancers for Oral Mucosal Drug Delivery," Drug Development and Industrial Pharmacy, Vol. 36, No. 3, 2010, pp. 254-282. doi:10.3109/03639040903117348

[18] D. Q. M. Craig, "A Review of Thermal Methods Used for the Analysis of the Crystal Form, Solution Thermodynamics and Glass-Transition Behavior of Polyethylene Glycols," Thermochimica Acta, Vol. 248, 1995, pp. 189203. doi:10.1016/0040-6031(94)01886-L

[19] J. S. Boateng, H. N. E. Stevens, G. M. Eccleston, A. D.
Auffret, M. J. Humphrey and K. H. Matthews, "Development and Mechanical Characterization of Solvent-Cast Polymeric Films as Potential Drug Delivery Systems to Mucosal Surfaces," Drug Development and Industrial Pharmacy, Vol. 35, No. 8, 2009, pp. 986-996. doi:10.1080/03639040902744704

[20] K. Huynh-Ba, "Handbook of Stability Testing in Pharmaceutical Development: Regulations, Methodologies, and Best Practices," Springer, 2009, pp. 248-250. doi:10.1007/978-0-387-85627-8

[21] G. Wypych, "Handbook of Plasticizers," ChemTec, 2004, pp. 218-220.

[22] B. C. Hancock and M. Parks, "What Is the True Solubility Advantage for Amorphous Pharmaceuticals?" Pharmaceutical Research, Vol. 17, No. 4, 2000, pp. 397-404. doi:10.1023/A:1007516718048

[23] L. Yu, "Amorphous pharmaceutical Solids: Preparation, Characterization and Stabilization," Advanced Drug Delivery Reviews, Vol. 48, No. 1, 2001, pp. 27-42. doi:10.1016/S0169-409X(01)00098-9

[24] O. K. C. Tsui, T. P. Russel and C. J. Hawker, "Effect of Polymer-Substrate Interactions on the Glass Transition of Polymer Thin Films," 3rd International Symposium on Slow Dynamics in Complex Systems, Proceedings AIP Conference, Vol. 708, 2004, pp. 598-600.

[25] S. Farmer, P. Anderson, P. Burns and R. Velagaleti, "Forced Degradation of Ibuprofen in Bulk Drug and Tablets," Pharmaceutical Technology, Vol. 32, 2002, pp. 28-42.

[26] W. C. Cory, C. Harris and S. Martinez, "Accelerated Degradation of Ibuprofen in Tablets," Pharmaceutical Development and Technology, Vol. 15, No. 6, 2010, pp. 636-643. doi:10.3109/10837450903426518

[27] J. S. Boateng, K. H. Matthews, A. D. Auffret, M. J. Humphrey, H. N. E. Stevens and G. M. Eccleston, "In Vitro Drug Release Studies of Polymeric Freeze-Dried Wafers and Solvent-Cast Films Using Paracetamol as a Model Soluble Drug," International Journal of Pharmaceutics, Vol. 378, No. 1-2, 2009, pp. 66-72. doi:10.1016/j.ijpharm.2009.05.038

[28] J. Siepmann and N. A. Peppas, "Modeling of Drug Release from Delivery Systems Based on Hydroxypropylmethylcellulose (HPMC)," Advanced Drug Delivery Reviews, Vol. 48, No. 2-3, 2001, pp. 139-157. doi:10.1016/S0169-409X(01)00112-0 